ISSN: 2162-3104 Print/ ISSN: 2166-3750 Online

Volume 8, Issue 1 (2018), pp. 431-452

(C) Journal of International Students

http://jistudents.org/

doi: 10.5281/zenodo. 1134324

\title{
Okinawan Consciousness and Identity Salience and Development among Okinawan University Students Studying in Hawai'i
}

\author{
Kazufumi Taira \\ Lois A Yamauchi \\ University of Hawai' $i$ at Mānoa, United States
}

\begin{abstract}
After Japan's annexation in 1879, Okinawa came under the unprecedented influence of Japanization. This research examined how learning in Hawai ' $i$ influenced the Okinawan sense of identity of 11 Okinawan students. Grounded theory analysis of interview transcripts indicated that students became more conscious as Okinawan through encounters and interactions with local people, including Okinawans, and Hawaiians in Hawai' $i$, and Okinawan events and activities there. Participating in an Okinawan club at the university provided opportunities for the students to express their Okinawan identity, interact with club members, and take responsibility as representatives of Okinawa, which promoted students' Okinawan consciousness and identity salience.
\end{abstract}

Keywords: grounded theory, identity development, identity salience, international students, Okinawan consciousness, Okinawan identity

Okinawan identity is related to the sociohistorical and political contexts of Okinawa. Okinawa used to run the distinct state, "the Kingdom of Ryūkyū" (Takara, 1998). Japan annexed Ryūkyū, establishing the Okinawa Prefecture in 1879. After the annexation, assimilation and Japanization were promoted through various means, including education and language (Fujisawa, 2000; Kondo, 2006; Oguma, 1998), administration (Matsushima, 2014), and 
discrimination (Nomura, 2007).

Soon after the U.S. military landed during the Pacific War, Okinawa was cut off from Japan by the U.S. Navy Admiral Nimitz's 1945 proclamation. The 1952 San Francisco Peace Treaty placed Okinawa under the U.S. administration, and the U.S. military ruled the region for 27 years from 1945 to 1972 . Okinawa was a colony of the U.S. military in terms of deprivation of land, U.S. military high commissioner' final decisions under the system of military dictatorship, crimes by U.S. military personnel, and a politico-economic system that subjected Okinawans to the U. S. military economy (Matsushima, 2012). During the U.S. military control, the movements for a reversion back to Japan took place to free Okinawa from the U.S. military rule, and Japanization was promoted to achieve that goal (Okudaira, 2010; Yara, 1977).

Okinawa reverted to the Japanese administration in 1972. At the summit with President Nixon in November 1969, Japanese Prime Minister Satō secured an agreement on Okinawa's 1972 reversion (Arasaki, 2005), and Japan and the U.S. signed "the Okinawa Reversion Agreement" (Okinawa Henkan Kyōtei), or Agreement Between the United States of America and Japan Concerning the Ryūkyū Islands and the Daitō Islands (Tanji, 2007). However, Prime Minister Satō's repeated promises for the U.S. military bases "at mainland level" (hondo-nami) and "free of nuclear weapons" (kaku-nuki) did not materialize after the reversion (Johnson, 1999; Tanji, 2007). The imposition of a politico-economic and cultural system paved the way for the assimilation of the Okinawans (Matsushima, 2012). The Japanese government continued a colonial rule in Okinawa by maintaining U.S. military bases, adopting the Japanese legal system, and taking politico-economic control (Matsushima, 2012).

It is likely that the process of assimilation and Japanization impacted identities among Okinawans. Lim's (2010) research revealed that young people in Okinawa showed a dual identification of being Okinawan and Japanese, which was full of complexities. According to his 2007 research, $45.2 \%$ of young people, ages 18 to 25 in Okinawa said that they were both Okinawan and Japanese, $28.0 \%$ of them identified themselves as Okinawan, and $23.7 \%$ of them considered themselves as Japanese (Lim, 2010). When asked to rate, on a scale of 0 to 10 , the extent to which they identified themselves as Okinawans or Japanese, they responded 6.7 and 6.6, respectively. Thus, contemporary Okinawan university students who grew up in Okinawa may find their sense of identity complex-being Okinawan, Okinawan with a mix of Japanese, or solely Japanese. 
In the current research, participants were those who grew up in Okinawan society under sociohistorical and political influence of Japanization and colonization and the Japanese influence after Okinawa's reversion back to the Japanese administration. The purpose of this study was to examine how Okinawan university students' experiences in Hawai' $i$ and an Okinawan club on campus of a university in Hawai' $i$ influenced their Okinawan consciousness and identity.

\section{LITERATURE REVIEW}

\section{Literature Review and Grounded Theory Analysis}

In the following sections, the researchers review relevant literature on theory and research on identity development. As the researchers employed an inductive data analytic approach using grounded theory techniques (Corbin \& Strauss, 2014), they will clarify the purpose of this review. The conduct of a literature review before data collection and analysis is controversial among researchers who use grounded theory (Elliott \& Higgins, 2012; Luckerhoff \& Guillemette, 2011; Mitchell, 2014; Suddaby, 2006). One of the characteristics of grounded theory is its emphasis on inductive inquiry, uncovering concepts deriving from the raw data of participants' perspectives. Glaser (1992), a co-founder of grounded theory, maintains that researchers should not review literature before data collection due to concerns that they may contaminate, constrain, or impede category generation. However, McGhee, Marland, and Atkinson's (2007) summary of arguments for literature review before analyses includes avoiding conceptual and methodological pitfalls, assessing whether grounded theory is an appropriate method, and developing a sense of open mindedness.

Also, some researchers discuss that literature can be useful for certain purposes. Lucherhoff and Guillemette's (2011) study showed that researchers can reference literature, so as to avoid reinventing what is already known, clarify disciplinary perspectives, define terms, draw "sensitizing concepts," collect data from relevant areas, compare "ideas" to those that emerge, and enrich the discussion of results. Corbin and Strauss (2014) state that research, theoretical, philosophical, professional, and disciplinary literature may be used to make comparisons, enhance sensitivity, provide descriptive analysis, supply questions for initial observations and interviews, stimulate questions during the analysis, and confirm findings. 
The researchers' intention for the current literature review was not to build hypotheses or "force" data into existing conceptual or theoretical frameworks. Rather, they reviewed the literature to make comparisons, enhance sensitivity, illustrate the significance of their research in the literature, and enrich the discussion of results. The researchers followed the caveat to abstain from hypothesis testing that is based on knowledge gained from the literature review and avoid prejudice and analyses that are contaminated by preconceived notions (Luckerhoff \& Guillemette, 2011; Suddaby, 2006).

\section{Study Abroad and National and Ethnic Identity}

The researchers reviewed literature on study abroad to understand how students who studied in other countries and regions became more conscious of their identities. Dolby $(2004,2005,2007)$ analyzed reflections of U.S. college students who studied abroad, and discussed how the students negotiated, questioned, and reconstructed their national identity. Similarly, studying abroad in Cuba influenced U.S. college students' reexamination of their national identity (France \& Rogers, 2012).

Gao (2011) examined reformation of Chinese national identities among Chinese students who studied abroad in Britain. The results seem to reveal a heightened sense of Chinese national identity and patriotism. Also, interactions with students from Japan and Taiwan provided the Chinese students with opportunities to reexamine their own attitudes and values that were built upon a national identity founded on history and politics.

Focusing on Japanese university students who studied abroad, Uematsu (2009) concluded that these students showed a greater sense of belonging, affirmation, and exploration of being Japanese than before they studied abroad. Uematsu (2010) also compared Japanese university students who studied in Japan and abroad and found that ethnic identity of Japanese students studying abroad was more salient than that of Japanese university students studying in their home country.

Different from previous research, the current study analyzed and focused on a minority group's identity that has been sociohistorically and politically suppressed. Specifically, the researchers examined Okinawan students studying in Hawai' $i$ and participating in activities that may have influenced their Okinawan identities. Although the term "study abroad" is often used to describe semester- and year-long study in another country, the researchers are using it to describe Okinawan students enrolled in a program 
for two semesters as well as an entire higher education program in another country.

\section{Identity Development and Ethnic Identity}

Personal experiences, social environments, group affiliations, and histories are important factors related to identity development. Cooper (2011) conceptualized identity development in the following way:

"Identity development can be seen in terms of personal exploration and commitment in domains such as careers, gender role, sexuality, political ideology, and religious beliefs, and as part of a collective process of categorizing one's membership in social groups. In addition, societal, institutional, and intergenerational forces can affect identity development." (p. 11)

Referring to Erikson's (1968) pioneering work on identity development, Cooper (2011) pointed to the influences of the histories of individuals, families, cultural communities, and societies on shaping identity development. This perspective also considers opportunities and constraints, and individual variations in the process.

Phinney (2002) suggested that ethnic identity is comprised of three main components: (a) ethnic self-identification or self-labeling, (b) the subjective sense of belonging to an ethnic group and feelings about group membership, and (c) the level of ethnic identity development. These components are similar to Cooper's (2011) concept of identity development in terms of self-identification, membership, and developmental aspect.

\section{RESEARCH METHOD}

\section{Participants}

Participants included 11 Okinawan university students, eight of whom were female. The participants' ages ranged from 22-37 years. All of the participants grew up in Okinawa and were undergraduate or graduate students studying at a university in Hawai'i. All were members of the Okinawan Club, and seven were former coordinators of the Club. The names of the Club and all the people's names in this paper are pseudonyms. 


\section{Okinawan Club}

The Okinawan Club was a club composed of those who were interested in learning about Okinawa, mostly university students. The Okinawan Club promoted knowledge about Okinawa and support for members. Although numbers and types of activities on campus varied across the years, coordinators organized study sessions and other activities to learn about Okinawa, and social gatherings involving sharing through potlucks.

\section{Interviews}

The first author interviewed participants about how they describe themselves - as Okinawan, Japanese, Asian, or another member of a group. Also, the author asked about the activities in the Okinawan Club, and how these have influenced their identities as Okinawans. The first author was an Okinawan Club member and knew the participants before the interviews through their Club activities. He contacted former and current Club members to recruit them for participation in this research. The first author interviewed the seven participants who were former Okinawan Club coordinators first by focusing on their experiences in the Club.

Based on the initial responses, the researchers employed a grounded theory technique of questioning to gain a direction for theoretical sampling (Corbin \& Strauss, 2014). Theoretical sampling is data recollection based on concepts and analyses that are constructed from the data already gathered. Theoretical sampling continues until it reached a level of theoretical saturation. The researchers were curious about the following questions, "Do general club members have similar or different experiences compared to those of coordinators'?" Also, the researchers wondered, "Does Hawai'i in general influence Okinawan identity among Okinawan university students?" This question derived from the constructed context of "Hawai'i as a historical, social, and cultural environment" based on responses from the coordinators. As the interviewees in the first interviews spoke about their experiences in the broader context of Hawai' $i$ influencing their consciousness and identities, this broadened the researchers' interests in the Okinawan Club to Hawai'i, in general. Finally, the researchers interviewed the four remaining participants, who had been general club members but not coordinators, using the same questions and new ones, including the Hawai' $i$ context.

The interviews were approximately $50 \mathrm{~min}$ long, conducted in Japanese. For this paper, the quotes used resulted from the translation from 
Japanese to English. The University of Hawai'i Committee on Human Studies approved this research.

\section{Data Analysis}

The researchers employed analytic techniques and procedures from grounded theory (Corbin \& Strauss, 2014) for data analyses. As Corbin emphasizes, the researchers used analytic techniques as tools in a flexible, less structured way, rather than as directives. They analyzed data from constructivist and interpretative standpoints, acknowledging their subjectivities and the existence of multiple interpretations and perspectives. The researchers did not treat concepts as "reality" waiting to be discovered, but rather they constructed concepts based on stories that the participants constructed.

In this research, the researchers coded categories, subcategories, conditions, contexts, and a central category. Categories are higher-level and more abstract concepts. Subcategories are more specific and detailed. Conditions "refer to the perceived reasons that persons give for why things happen and the explanations that they give for why they respond in the manner that they do through action-interaction" (Corbin \& Strauss, 2014, p. 158). The researchers related categories, subcategories, conditions, and contexts that located and explained "action-interaction within a background of conditions and anticipated consequences" (Corbin \& Strauss, 2014, p. $153)$, to develop a core category that was abstract, representing the key theme of the research and relating all other concepts to the theme.

Different from quantitative researchers, qualitative researchers are typically not concerned with generalizability to a larger population (Corbin $\&$ Strauss, 2014). Rather, qualitative research interests in grounded theory focus on representativeness of concepts, and the development of these concepts. Thus, the purpose of the analysis was not to generalize the result to all other Okinawan university students studying in Hawai' $i$, but to identify, construct, and interpret concepts based on the sample, analyze the relationships of the concpets, and develop the concepts through further sampling.

\section{RESULTS}

The first author classified conditions, categories, and subcategories into two contexts in which the participants' consciousness and identities as Okinawans became more salient: "Hawai'i as a historical, social, cultural, 
and political environment" and "the Okinawan Club as a space promoting Okinawan consciousness and identity." An "environment" is used for Hawai' $i$ in general to indicate that Okinawan students came to a geographically and culturally different environment where they experienced Okinawan consciousness and identity salience and development. "Space" represented the Okinawan Club, which was created for opportunities to learn about Okinawa. The researchers constructed these contexts based on the conditions, categories, and subcategories resulting from the coding of the students' experiences.

\section{Hawai'i as a Historical, Social, Cultural, and Political Environment}

In this context, the researchers identified three conditions, "being in a culturally and ethnically diverse environment," "Okinawans and Okinawan cultures in Hawai'i," and "learning about Hawaiians."

\section{Being in a Culturally and Ethnically Diverse Environment}

When Mari, a coordinator, moved from the relatively homogenous environment of Okinawa to a culturally and ethnically diverse society of Hawai' $i$, she reported becoming more conscious as Okinawan through social interactions with people in Hawai'i. Mari said she experienced a sense of belonging to Okinawa and connection to her Okinawan identity when she was surrounded by culturally and ethnically diverse people in Hawai ${ }^{6} \mathrm{i}$ :

"When I lived in Hawai'i, there were various races and ethnic
groups other than Okinawans, and Okinawan was a group within
all of that. When I was surrounded by various races and
backgrounds, I was thinking where I belonged, and I realized that I
belonged to Okinawa. . . I feared losing the place I belonged to in
the foreign place. . . In that situation, I clung strongly to Okinawan
identity. But when I came back to Okinawa, everybody is Okinawan.
Okinawans are in the majority, so I do not need to worry about this
problem. . . I do not need to struggle with identity. I feel like the
problem was gone after I came back to Okinawa."

Based on her experience, the researchers constructed a category of "being not-the-majority" in this condition. 


\section{Okinawans and Okinawan Cultures in Hawai'i}

Hawai' $i$ was also an environment where participants experienced Okinawan activities, met Okinawan descendants and others who recognize them as Okinawan. In this condition, the researchers constructed three categories, such as "Okinawan events and activities," "people's recognition of Okinawa," and "interactions with Okinawan descendants."

\section{Okinawan Events and Activities}

When asked if she described herself as Okinawan, Japanese, Asian, or other group member, Mitsuko, a coordinator, spontaneously rated her Okinawan identity as seven and her Japanese identity as three. She mentioned that her Okinawan identity developed after she came to Hawai' $i$. Mitsuko's Okinawan identity became stronger especially in the first period of her stay in Hawai' $i$. In response to a question about the situations that made her Okinawan identity salient, Mitsuko responded:

"I think the Okinawan Club started at that time. We had to do something as students to gain steam. I became conscious of being Okinawan as an extension of this. Also. . . what inspired me to study migration studies, but there were many Okinawan descendants in Hawai' ' , and people in Hawai ' $i$ distinguished Okinawan people and Japanese people, don't they? There are associations of each prefecture, festival, and there is a day for Okinawan elders for nursing home gathering. I was surprised and shocked, so I started migration studies specializing in Okinawa. I encountered these situations several times."

\section{People's Recognition of Okinawans}

When asked, "Do you describe yourself as an Okinawan, Japanese, Asian, or other group member?" Yoriko and Yuri, both coordinators, responded that they described themselves as Okinawan because people in Hawai'i recognized Okinawans more than people on the continental U.S. For example, Yoriko remarked:

"This is a common case, but if I am asked, "Where are you from?" I say "I am from Okinawa." But if they say, "Oh, Japan?" I do not deny, something like that. . . I expect, or think that it is Hawai ' $i$, so 
people know about Okinawa, and if they do not, I explain. But maybe ... when I was on the mainland, I said I am Japanese."

Yoriko mentioned her being Okinawan when she was in Hawai'i. This differed if she was on the continental United States. Yuri also shared her experience:

"Well, if I am in Hawai 'i, I say I am Uchinaanchu [Okinawans in Okinawa]. But if not in Hawai'i, but on the mainland, America, different countries, I say I am from Okinawa, Japan, Okinawa in Japan. I mention Okinawa, but I add Japan to the explanation for sure because I think people do not know."

Yuri's self-identification is different from Yoriko's. Yuri introduced herself as from Okinawa in all locations. However, the option for her to be from Japan emerged when she was on the continental U.S. or in other countries where she thought people did not recognize Okinawa. This emergence of being from Japan in other places than Hawai'i might have made it less accessible for her to identify with being from Okinawa because of people's lack of knowledge about Okinawa.

Other club members also had similar experiences. Eri, a general member, remarked that in Hawai'i, she would tell people she was from Okinawa, "I said Okinawa most of the time because everybody knows." Another general member, Takashi, stated:

"When I went shopping at stores and in Waikiki, a clerk asked me where I was from, and I said from Okinawa, and the clerk was like "Okinawa!" And, well, there was a clerk who had Okinawan blood among other clerks, and it was something like welcoming, not exactly, but that was like "you guys were from Okinawa." At that time, I recognized that people distinguish Japanese and Okinawans here, which was impressive in retrospect."

Because people in Hawai'i were likely to recognize Okinawa and distinguish Okinawans and Japanese, it was more accessible for students to be Okinawan in those situations. With this, the researchers constructed a subcategory of "accessibility to being Okinawan."

\section{Interactions with Okinawan Descendants}

Masako, a general member, Eri, and Takashi described their interactions with Okinawan descendants in Hawai' $i$, and how they influenced their Okinawan identity. Masako said that talking with Okinawan 
descendants made her think about Okinawa and about being Okinawan. Eri explained that she met Okinawan descendants and learned a lot about Okinawan history and culture by talking with them. Takashi had a somewhat different experience:

"When I interacted with Uchinaanchu I faced a lot of questions such as 'Do you speak Uchinaaguchi? Can you do eisaa [folk dance]? Can you do kumiodori [traditional Ryūkyūan dance]?' and I said I could not. At that time, I felt that Uchinaanchu's faces looked like, very regretful, and I cannot forget it. . . While looking at sad faces among Uchinaanchu, I felt my identity.'

Takashi felt his Okinawan identity when he thought he disappointed Okinawans in Hawai' $i$ for not being able to show some aspects of Okinawan culture. These students' experiences described the influence of interactions with Okinawans in Hawai' $i$ on their Okinawan consciousness and identity.

\section{Learning About Hawaiians}

Takashi described learning about Native Hawaiian's identity and its influence on his own: "Hawaiians do not say they are Americans, and I was confronted by their strong identity that they are Hawaiians." This made him think that perhaps Okinawans should have identity themselves as strongly and noted that "through Hawaiians' strong identity. . . I felt my identity." In this condition, a category of "encountering strong Hawaiian identity" was constructed.

\section{The Okinawan Club as a Space Promoting Okinawan Consciousness and Identity}

This context includes seven conditions such as, "space to be able to express Okinawan identity," "interacting with club members," "increased opportunities to think and learn about Okinawa," "teaching others about Okinawa," "taking a role as a representative of Okinawa," "sharing cultural heritage," and "cultural activities."

\section{Space To Be Able To Express Okinawan Identity}

Participants mentioned that the Okinawan Club was a space where they became more conscious of their Okinawan identity. For example, Mitsuko explained that: 
"[T]he Okinawan Club was the space where I expressed Okinawan identity. . . when we are with the Okinawan Club members, Okinawan consciousness becomes stronger, right? . . Expressing oneself as a person or, a space to be conscious of Okinawa and myself as a person. ... Of course, I learned about Okinawa through Club activities, and the Club was one of the motives of being more conscious of myself as Okinawa[n]."

Yuri also described the Okinawan Club as a space where she could openly express her Okinawan identity.

"Although my identity as Okinawan did not change in particular, I felt proud and could express it without hesitation. It was okay to talk about Okinawa without hesitation, and I felt a sense of ease in these discussions. When I was in Okinawa, I had only a few people whom I could talk to about these issues. . . . Among most of my friends, I perceived that they ignored me when we talked about U.S. military base issues and Uchinaaguchi. . . My impression is that discussing those things, like identity, or something Okinawan in Okinawa, was sort of taboo."

\section{Increased Opportunities To Think and Learn About Okinawa}

Yoshio, a general member, mentioned that through his participation in Okinawan Club activities, opportunities to think about Okinawa increased, which promoted his Okinawan identity: "Because opportunities to think about Okinawa increased and . . . my feeling that I had to study more [about Okinawa] became stronger, so I think my identity became stronger."

\section{Teaching Others About Okinawa}

Okinawan Club activities provided opportunities for members to meet others who did not know much about Okinawa and prompted members to be able to teach these people about Okinawa. Yoshio described such an experience: "I felt my identity when I expressed Okinawa to those who did not know about Okinawa." In these situations, Yoshio's Okinawan identity became more salient. 


\section{Interacting with Club Members}

For some participants, interactions with Okinawan Club members influenced their Okinawan consciousness to become stronger and more salient. As shown in the condition of "space to be able to express Okinawan identity," Mitsuko said her Okinawan consciousness became stronger when she was with other club members. Interactions with Club members also influenced Yoriko to become more conscious about her attitudes about where she was from:

"Well, the most influential were senior members. Talking with these people, listening to Okinawan Club senior members, helped me to realize my indifference to cultural things, research on immigration, politics, and history. I recognized that I had abandoned my responsibility to learn, although I thought I loved Okinawa so much. Through talking with those who were seriously involved in those issues and discussed their concerns, I developed political awareness. I could no longer be indifferent, I had to think seriously. ... I began to feel that it was my responsibility as a person from Okinawa to take an interest in [military] base issues and politics, and think seriously."

In this condition, the researchers constructed categories of "recognition" and "responsibility," subsuming subcategories of "indifference to Okinawan cultures and issues" and "be interested in Okinawan issues and politics," respectively.

\section{Taking a Role as a Representative of Okinawa}

In this condition, the researchers constructed a category of "responsibility." Yoriko said that the Okinawan Club influenced her adoption of a role as a representative of Okinawa. As a coordinator, Yoriko said she felt responsible to know more about Okinawa, which is a subcategory of responsibility to "know more about Okinawa."

"Being a coordinator meant to represent young Okinawans and to be a front person of that place. It was hard to say that I did not know about Okinawa. I needed to have knowledge about it to some extent, and to always have my opinions about it to some degree, and I had to think about that responsibility." 
As a Club coordinator, Yoriko also participated in a cultural event that showcased diverse cultures through performances and booths. She noted that the previous year, there was no representation of Okinawans. "I . . . thought that we had to do [it], and signed up for it. . . Having no Okinawa team meant no show of assertiveness. Okinawa, we are Okinawa." Yoriko wanted Okinawans to be more visible and for others to know more about them, which is another subcategory of responsibility to "make Okinawa visible."

\section{Sharing Cultural Heritage}

As an answer to the interview question "While being a member of the club, when did you think about Okinawan identity?" Masako mentioned sharing of dialect and intonation with other Club members:

"Maybe, I think we can use dialect among Okinawans. Maybe when we use it there, and intonation. Japan, I am careful of it when I talk to other Japanese students. Intonation.... among Okinawan members, naturally, I speak as usual. Without care."

The Okinawan Club was a space where Masako felt she could speak in her dialect and using intonation associated with that way of speaking. The researchers constructed a category of "sharing dialect and intonation" in this condition. It was a space to share this cultural heritage with other Club members.

\section{Cultural Activities}

Masako expressed her experience of seeing eisaa, which club members performed: "Thinking about club activities, at that time, eisaa, when I got excited when I saw eisaa, when my heart beat fast, I think I am Uchinaanchu." Seeing other Club members performing eisaa had an impact on not only physical reaction of heartbeat but also psychological one of selfidentification as Okinawan.

\section{Integration}

In this section, the researchers conducted an integration by which they weave the concepts around a core category. A core category is an abstract concept that relates to all other concepts, and represents the main concept of the research. For this study, the researchers coded a core category 
as "being more conscious as Okinawan in Hawai'i." Figure 1 shows an integrative diagram to demonstrate the relationships of the core category and contexts with the categories of "Okinawan consciousness and identity salience" and "Okinawan identity development." These are constructed based on the data that suggested that participants' experiences in Hawai' $i$ and as members of the Okinawan Club increased their consciousness as Okinawan in Hawai'i.

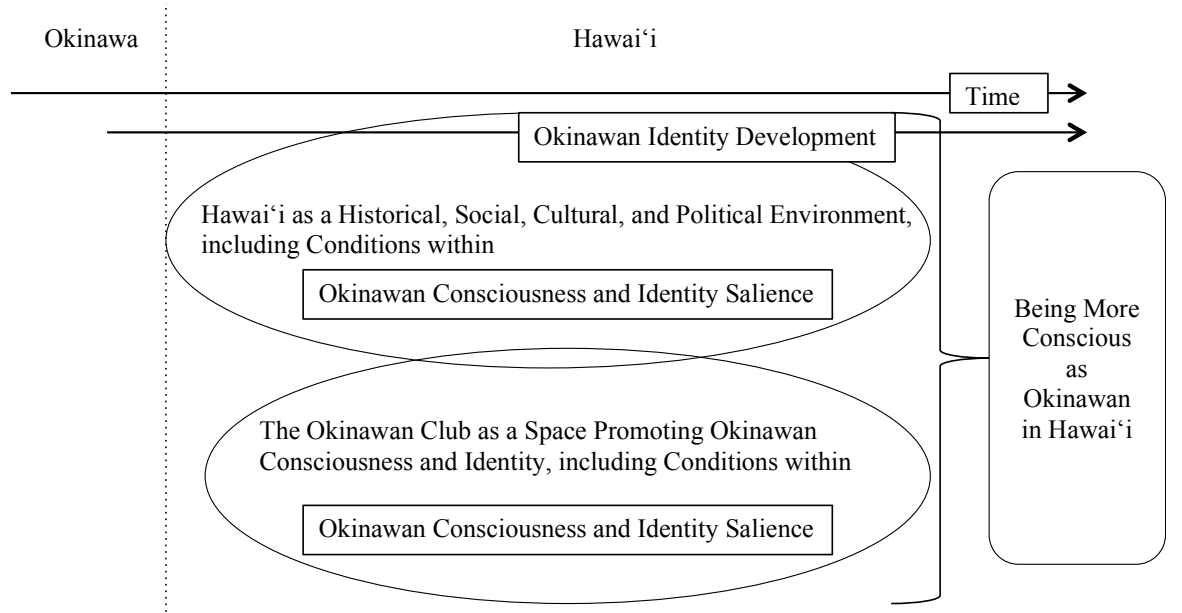

Figure 1. Integrative diagram of being more conscious as Okinawan in Hawai'i.

When participants came to Hawai' $i$ to study abroad, many of them reflected on their identities as Okinawan. One student mentioned that her Okinawan identity developed after she came from Okinawa to Hawai'i. As a multi-ethnic environment, Hawai'i promoted the student's thinking about her Okinawan identity because she was no longer in the majority compared to being in Okinawa. This situation demonstrates the category of "being notthe-majority" as explained by the condition of "being in a culturally and ethnically diverse environment." Given the sociohistorical context of Okinawan immigration to Hawai' $i$, many viewed Okinawan as an ethnic category separate from Japanese. The recognition of Okinawan as an ethnic group happened more often in Hawai' $i$ than on the continental U.S. and contributed to the students' increased self-identification. This finding led to the category "people's recognition of Okinawans," subsuming the subcategory of "accessibility to being Okinawan," within the condition of "Okinawans and Okinawan cultures in Hawai'i." This condition also 
includes the categories of "Okinawan events and activities" and "interactions with Okinawan descendants." One student experienced a heightened sense of Okinawan identity in Okinawan events and activities in Hawai'i. Also, some students had opportunities to interact and learn from Okinawan descendants through which they became more conscious as Okinawan. In the condition of "learning about Hawaiians," a student encountered Hawaiians' strong identity and was inspired to think that Okinawans also had to have strong identity, which depicts the category of "encountering strong Hawaiian identity." Action-interaction within these conditions, which involves encounters and interactions with local people, Okinawans, Hawaiians, and Okinawan events and activities in Hawai'i, heightened a sense of Okinawan consciousness and identity among the students.

As for the context of the Okinawan Club in Hawai' $i$, the Club functioned as a space promoting Okinawan consciousness and identity among Okinawan university students. For instance, students could express their Okinawan identity, think more about Okinawa, and teach others about Okinawa. As such, the researchers constructed the conditions of "space to be able to express Okinawan identity," "increased opportunities to think about Okinawa," and "teaching others about Okinawa." Another condition of "interacting with club members" included categories of "recognition" and "responsibility," subsuming subcategories of "indifference to Okinawan cultures and issues" and "be interested in Okinawan issues and politics," respectively. As a coordinator, a student expressed her experience of salient Okinawan identity, as depicted in the condition of "taking a role as a representative of Okinawa" that involved the category of "responsibility," subsuming the subcategories of "know about Okinawa as a representative" and "make Okinawa visible." These concepts depicted how social interactions with other club members promoted learning about Okinawa and responsibility. The last two conditions involved "sharing cultural heritage," including the category of "sharing dialect and intonation," and "cultural activities" that stimulated student's consciousness as Okinawan. The context of "Okinawan Club as a space promoting Okinawan consciousness and identity" encompassed all these conditions, categories, and subcategories. Participation in Okinawan activities and social interactions with club members within the conditions, as demonstration of action-interaction, were the factors that stimulated Okinawan consciousness and identity, as a consequence.

Including general club members, in addition to the coordinators, expanded the conditions and categories in the both contexts. The main 
difference in concepts between coordinators and general club members was the condition of "taking a role as a representative of Okinawa," which included the category of "responsibility" and subcategories of "know more about Okinawa" and "make Okinawa visible," because only coordinators took that role in the Club.

\section{DISCUSSION AND CONCLUSION}

Hawai' $\mathrm{i}$ is a culturally and ethnically diverse society. According to the 2010 census, the race/ethnicity of residents included White (41.5\%), Filipino (25.1\%), Japanese (23.0\%), Native Hawaiian (21.3\%), and Chinese (14.7\%) (The Office of Hawaiian Affairs, 2011). Moving from a more homogenous setting of Okinawa to Hawai' $i$ appeared to influence the Okinawan participants' awareness of their own ethnic backgrounds in a more ethnically and culturally diverse environment. When a group shares cultural values, everyone acts in ways that are expected, so there is less of a need to think about culture (Brislin, 2000). It is when individuals encounter those who have different expectations and ways of being that culture becomes more apparent.

\section{Study Abroad in Hawai'i and Its Impact on Okinawan Identity}

Participants in the current study reported heightened consciousness of their Okinawan identity when they studied in Hawai' $i$. This is similar to research indicating that studying in another country promoted college students' reflections of their national identity (Dolby, 2004, 2005, 2007). In some cases, studying abroad increased students' national identities and patriotism (Gao, 2011) and influenced students' affinities for, and explorations of, their national identities (Uematsu, 2009, 2010).

When Okinawan students in the current investigation came to study in Hawai' $i$, they were surprised that people recognized Okinawans as distinct from the Japanese. This recognition appeared to have increased their consciousness and self-identification as Okinawans. Residents in Hawai' ${ }^{\prime}$ often distinguished Okinawan as a separate ethnic group, different from Japanese. In Hawai'i, participants became more conscious as Okinawan through interactions with descendants of Okinawan immigrants. The maintenance of Okinawan ethnic community and identity (Ueunten, 1989) and a resurgence of pride and awareness of Okinawan identity among Hawai'i-born Okinawan descendants (Kaneshiro, 2002) may have influenced participants' identity directly or indirectly. 
The integrative diagram that the researchers developed from the concepts (see Figure 1) suggests that the constructed concepts influenced the Okinawan students' consciousness and self-identification over time. However, the influence of such concepts is complicated, with certain concepts exerting more influence on particular individuals at different points in time and moderated by other concepts. For example, although Mitsuko mentioned a developmental aspect of her Okinawan identity after coming to Hawai' $i$, she also pointed out that it fluctuated and suggested that there were situational aspects of her Okinawan identity in Hawai'i. Mitsuko stated that she was more conscious as Okinawan at the beginning of her study in Hawai'i, but that her identity was less salient after that period. Future research may advance the understandings of how Okinawan consciousness and identity fluctuate over time and may help to identify particular points in time that are important for such development.

\section{Interactions Promoting Identity}

Vygotsky (1978) suggested that social activity precedes psychological development. That is, interactions with others can lead to individuals appropriating the ways of being and acting that are demonstrated and communicated through shared activities. Yamauchi (2005) explains how interactions within a cultural community are passed on to new generations, as newcomers and young people appropriate the community's values and ways of being.

Participants in the current study reported that joining Okinawan events and activities and interactions with Club members who were enthusiastic and knowledgeable about Okinawa influenced their sense of their Okinawan identity.

\section{Inspiration by Hawaiians}

Hawai' $i$ is home to indigenous people who experienced colonization and a revitalization of culture and pride. There are parallels between the colonization of Hawai'i by the U.S. and the colonization of Okinawa by Japan. Studying in Hawai'i created opportunities for one participant to encounter Native Hawaiians' identity. Takashi mentioned that observing the strong identity of Hawaiians influenced him to think about how Okinawans can also have a strong identity. Indeed, marginalized peoples report being inspired by similar groups, including influences of Māori language 
revitalization on Hawaiian language education, for example (Kame'elehiwa, 1992; Wilson \& Kamanā, 2006; Yamauchi, Ceppi, \& Lau-Smith, 1999).

In summary, the results of this investigation revealed concepts regarding identity salience and development among Okinawan university students studying in Hawai' $i$, which suggest that studying abroad in Hawai' $i$ may create opportunities for Okinawan students to explore things Okinawan and influenced their Okinawan consciousness and identity. As Cooper (2011) pointed out, although the traditional view of identity development is often described as a process of exploration of unconstrained opportunities, it is not the case that all young people, particularly those from less privileged backgrounds, are free to explore all identity options. When a group is marginalized, as is the case of Okinawans, there may be limited opportunities for individuals to explore their identities as Okinawans. Studying in Hawai' $i$ and participating in the Okinawan Club might increase such opportunities for these people.

\section{Limitations and Future Research}

Although the researchers constructed the concepts regarding Okinawan consciousness and identity salience and development based on the students' experiences, they do not claim to build a theory of it due to insufficiency to achieve saturation of the concepts. There is a need to expand the participants of this study beyond those Okinawan Club coordinators or general members to construct more concepts and enhance the constructed concepts regarding Okinawan consciousness and identity. Also, spaces, other than the Okinawan Club, may exist and be studied to determine if they promote Okinawan consciousness and identity. The researchers recommend exploring other spaces to enhance this research area. In addition, delving into the condition of "learning about Hawaiians" and the category of "Okinawan identity development" necessitates data to fully understand more the condition and category in order to refine the core category. Finally, this study investigated complexities of identity among Okinawans studying abroad, a historically marginalized group. The researchers suggest that future research further elucidate the complexities of identity among other international students who are also marginalized. Such research may lead to suggestions for student affairs professionals to address specific issues faced by these groups. 


\section{REFERENCES}

Arasaki, M. (2005). Okinawa gendaishi [Hisotry of modern Okinawa]. Tōkyō: Iwanami Shoten.

Brislin, R. (2000). Understanding culture's influence on behavior (2nd ed.). Belmont, CA: Wadsworth.

Cooper, C. R. (2011). Bridging multiple worlds: Cultures, identities, and pathways to college. New York: Oxford University Press.

Corbin, J., \& Strauss, A. (2014). Basics of qualitative research: Techniques and procedures for developing grounded theory (4th ed.). Los Angeles: Sage.

Dolby, N. (2004). Encountering an American self: Study abroad and national identity. Comparative Education Review, 48, 150-173. doi: 10.1086/ 382620

Dolby, N. (2005). Globalisation, identity, and nation: Australian and American undergraduates abroad. The Australian Educational Researcher, 32, 101117. doi: $10.1007 / \mathrm{BF} 03216815$

Dolby, N. (2007). Reflections on nation: American undergraduates and education abroad. Journal of Studies in International Education, 11, 141-156. doi: $10.1177 / 1028315306291944$

Elliott, N., \& Higgins, A. (2012). Surviving grounded theory research method in an academic world: Proposal writing and theoretical frameworks. The Grounded Theory Review, 11, 1-12.

Erikson, E. (1968). Identity: Youth and crisis. New York: Norton.

France, H., \& Rogers, L. (2012). Cuba study abroad: A pedagogical tool for reconstructing American national identity. International Studies Perspectives, 13, 390-407. doi: 10.1111/j.1528-3585.2012.00478.x

Fujisawa, K. (2000). Kindai Okinawa kyōiku no shikaku - Mondai shi teki saikousei no kokoromi [The perspective of education in Okinawa in the modern era Attempt to reconstruct criticism in history]. Tokyo: Shakai Hyōron Sha.

Gao, F. (2011). Exploring the reconstruction of Chinese learners' national identities in their English-language-learning journeys in Britain. Journal of Language, Identity \& Education, 10, 287-305. doi: 10.1080/15348458. 2011.614543

Glaser, B. G. (1992). Emergence vs forcing: Basics of grounded theory analysis. Mill Valley, CA: Sociology Press.

Johnson, C. (1999). Okinawa: Cold war island. Albuquerque: Japan Policy Research Institute.

Kame'elehiwa, L. K. (1992). Kula Kaiapuni: Hawaiian immersion schools. The Kamehameha Journal of Education, 3, 109-118.

Kaneshiro, N. (2002). Uchinanchu identity in Hawai'i. Social Process in Hawai 'i, $41,75-94$.

Kondo, K. (2006). Kindai Okinawa ni okeru kyoiku to kokumin togo [Education and national integration in modern Okinawa]. Sapporo: Hokkaido Shuppan Kai. 
Lim, J. C.-T. (2010). Chōsa kara mita Okinawa no wakamono no aidentiti [Research on identity among young Okinawans in the survey]. In M. Ishihara, I. Kina, \& S. Yamashiro (Eds.), Okinawa/Hawaii: Kontakuto zōn toshiteno tōsho [Okinawa and Hawai' $\mathrm{i}$ : Islands as the Contact Zone] (pp. 159-178). Tokyo: Sairyū Sha.

Luckerhoff, J., \& Guillemette, F. (2011). The conflicts between grounded theory requirements and institutional requirements for scientific research. The Qualitative Report, 16, 396-414. Retreived from http://nsuworks. nova.edu/tqr/vol16/iss $2 / 5 /$

Matsushima, Y. (2012). Ryūkyū dokuritsu heno michi - Shokuminchishugi ni aragau Ryūkyū nationalism [Road to Ryūkyū independence - Ryūkyū nationalism resistent to colonialism]. Kyōto: Hōritsu Bunka Sha.

Matsushima, Y. (2014). Ryūkȳu dokuritsu ron [Discussion of Ryūkyū independence]. Tōkyō: Basilico.

McGhee, G., Marland, G. R., \& Atkinson, J. (2007). Grounded theory research: Literature reviewing and reflexivity. Journal of Advanced Nursing, 60, 334-342. doi:10.1111/j.1365-2648.2007.04436.x

Mitchell, D., Jr. (2014). Advancing Grounded Theory: Using theoretical frameworks within Grounded Theory studies. The Qualitative Report, 19, $1-11$.

Nomura, K. (2007). Nihonjin toiu shokuminsha [Colonizers called Japanese]. In K. Nomura (Ed.), Shokuminsha e - Posuto koroniarizumu toiu chōhatsu [To the clonizers - Postcolonialism provocation] (pp. 27-71). Kyōto: Shōraisha.

Oguma, E. (1998). Nihonjin no kyōkai [The boundaries of "the Japanese"]. Tokyo: Shinyōsha.

Okudaira, H. (2010). Sengo Okinawa kyōiku undōshi - Fukki undō ni okeru Okinawa kyōsohkuinkai no hikari to kage - [The history of educational social movement in Okinawa's education after the war - The light and shadow in Okinawa Teachers' Association for social movement of reversion]. Naha: Bōdāinku.

Phinney, J. S. (2002). Ethnic identity and acculturation. In K. M. Chun, P. B. Organista, \& G. Marin (Eds.), Acculturation: Advances in theory, measurement, and applied research (pp. 63-81). Washington, DC: American Psychological Association.

Suddaby, R. (2006). From the editors: What grounded theory is not. Academy of Management Journal, 49, 633-642. doi: 10.5465/AMJ.2006.22083020

Takara, K. (1998). Ajia no nakano Ryūkyū Ōkoku [The Kingdom of Ryūkyū in Asia]. Tōkyō: Yoshikawa Kōbun Kan.

Tanaka, K. (2013). Japan's endangered languages still considered mere dialects. Global Voices. Retrieved from https://globalvoices.org/2014/03/01/japansendangered-languages-still-considered-mere-dialects/

Tanji, M. (2007). Myth, protest and struggle in Okinawa. New York: Routledge. 
The Office of Hawaiian Affairs. (2011). Population (US Census) by race-ethnicity and county in Hawai'i: 2010. Retrieved from http://www.ohadatabook. com/T01-09-13.pdf

Uematsu, A. (2009). Ibunka ni okeru minzoku aidentiti no kenzaika- Nihonjin ryūgakusei wo taishō tosita jūdanchōsa niyoru shitsuteki kentō- [Ethnic identity in cross-cultural situation: A longitudinal study about Japanese students abroad]. Proceedings: Science of Human Development for Restructuring the "Gap Widening Society," 4, 45-53.

Uematsu, A. (2010). Ibunka kankyo ni okeru minzoku aidentiti no yakuwariShūdan aidentiti to jiga aidentiti no kankei [The role of ethnic identity in cross-cultural environment: Relationship between group identity and ego identity]. The Japanese Journal of Personality, 19, 25-37.

Ueunten, W. (1989). The maintenance of the Okinawan ethnic community in Hawai ' $i$ (Unpublished master's thesis). University of Hawai' $i$, Honolulu.

Vygotsky, L. S. (1978). Mind in society: The development of higher mental process. Cambridge, MA: Harvard University Press.

Wilson, W. H., \& Kamanā, K. (2006). For the interest of the Hawaiians themselves": Reclaiming the benefits of Hawaiian-medium education. Hūlili: Multidisciplinary Research on Hawaiian Well-Being, 3(1), 153181.

Yamauchi, L. A. (2005). Culture matters: Research and development of culturally relevant instruction. In C. R. O'Donnel \& L. A. Yamauchi (Eds.), Culture and context in human behavior change: Theory, research, and practical application (pp. 103-125). New York: Peter Lang.

Yamauchi, L. A., Ceppi, A. K., \& Lau-Smith, J.-A. (1999). Sociohistorical influences on the development of Papahana Kaiapuni, the Hawaiian language. Journal of Education for Students Placed At Risk, 4, 27-46. doi: 10.1207/s15327671 espr0401_3

Yara, C. (1977). Yara Chōbyō kaikoroku [Yara Chōbyō's memoir]. Tōkyō: Asahi Shinbun Sha.

KAZUFUMI TAIRA is a $\mathrm{PhD}$ candidate in the Department of Educational Psychology at the University of Hawai' $i$ at Mānoa. His research interests include international education and identity salience and development. Email: kazufumi@hawaii.edu.

LOIS A. YAMAUCHI is a professor in the Department of Educational Psychology at the University of Hawai' $i$ at Mānoa. Her research focuses on cultural influences on learning and the educational experiences of students, teachers, and families from indigenous and other minority groups. Email: yamauchi@hawaii.edu 